\title{
A family with $N K X 2.5$ gene mutations presenting as familial atrial septal defect and atrioventricular block: A case report
}

\author{
Youn Young Choi', Min Hyung Woo', Gi Beom Kim", Mi Kyoung Song', Sang Yoon Lee', Eun Jung Bae', Murim Choi², and \\ Young-Sook Kim ${ }^{3,4}$ \\ 'Department of Pediatrics, Seoul National University Children's Hospital, Seoul National University College of Medicine, Seoul, Korea \\ ${ }^{2}$ Department of Biomedical Sciences, Seoul National University College of Medicine, Seoul, Korea \\ ${ }^{3}$ Computational Biology \& Bioinformatics Graduate Program, Duke University, Durham, NC, USA \\ ${ }^{4}$ Center for Genomic \& Computational Biology, Duke University, Durham, NC, USA
}

\begin{abstract}
Point mutations in the human cardiac homeobox gene $N K X 2.5$ are associated with familial atrial septal defect (ASD), atrioventricular (AV) conduction disturbance, as well as sudden cardiac death. To date, more than 60 NKX2.5 mutations have been documented, but there are no reports in Korea. We are reporting the first Korean family with ASD and AV block associated with a novel mutation in the NKX2.5 coding region. A 9-year-old boy presented with a slow and irregular pulse, and was diagnosed with secundum ASD and first degree AV block. The boy's father, who had a history of ASD correction surgery, presented with second degree AV block and atrial fibrillation. The boy's brother was also found to have secundum ASD and first degree AV block. There were two sudden deaths in the family. Genetic testing revealed a novel mutation of NKX2.5 in all affected members of the family.
\end{abstract}

Key words: Homeobox protein Nkx-2.5, Atrial heart septal defects, Atrioventricular block.

\section{Introduction}

Although the secundum atrial septal defect (ASD) is a common congenital heart disease (CHD), familial occurrence is rare. Heterozygous mutations in two genes, NKX2.5 and GATA4, have been identified to be causes for a subset of familial ASD through research on non-syndromic CHDs [1]. The homeobox gene $N K X 2.5$ is one of the earliest known genetic causes for CHD. The signature phenotype of NKX2.5 mutation is ASD with conduction disease or arrhythmia [2]. In addition, many different types and categories of cardiovascular anomalies, such as ventricular septal defect, tetralogy of Fallot, double outlet right ventricle, tricuspid valve abnormalities (including Ebstein's anomaly), and hypoplastic left heart syndrome, are documented $[1,3,4]$. Unlike the NKX2.5 mutation, the GATA4 mutation is important for heart formation rather than the conduction system, because it is less relevant to the atrioventricular (AV) block [5].

Received: May 11 2018, Revised: June 4 2018, Accepted: June 5 2018, Published: 30 June 2018

*Corresponding author: Gi Beom Kim, M.D., Ph.D (iD http://orcid.org/0000-0002-7880-280X

Department of Pediatrics, Seoul National University Children's Hospital, Seoul National University College of Medicine, 101 Daehak-ro, Jongno-gu, Seoul 03080, Korea.

Tel: +82-2-2072-0266, Fax: +82-2-743-3455, E-mail: ped9526@snu.ac.kr

Conflict of interest: The authors declare that they do not have any conflicts of interest.

(c) This is an open-access article distributed under the terms of the Creative Commons Attribution Non-Commercial License (http://creativecommons.org/licenses/by-nc/4.0/) which permits unrestricted non-commercial use, distribution, and reproduction in any medium, provided the original work is properly cited.

(c) Copyright 2018 by the Korean Society of Medical Genetics and Genomics 


\section{Case}

A previously healthy 9-year-old boy was admitted for percutaneous ASD device closure. Eight months before admission, he was noted to have slow and irregular heartbeats during sleep by his father. Although the boy did not complain of any specific cardiac symptom, first degree AV block was diagnosed after an electrocardiogram (ECG), and he was referred to Seoul National University Children's Hospital. ECG showed sinus rhythm with first degree AV block [6] (Fig. 1A; PR interval, 220 ms). Transthoracic echocardiogram revealed two holes of secundum ASD (Fig. 2A; maximum diameter, $10 \mathrm{~mm}$ ). We closed the defect percutaneously by implanting an Amplatzer septal occluder $(17 \mathrm{~mm}$; St. Jude Medical, Inc., St. Paul, MN, USA) at the larger ASD (arrow indicator on Fig. 2B) successfully without complication.

The patient's father previously underwent surgical ASD closure at 20 years old. One year prior to his son's admission (when he was 39 years old), he felt frequent dizziness and was diagnosed with second degree AV block (Mobitz I) and atrial fibrillation. He was referred to our hospital for pacemaker insertion. At that time, the maximum RR interval on the Holter monitor was 2.4 seconds. Radiofrequency catheter ablation was performed for atrial fibrillation, but the dizziness became worse. Eight months after radiofrequency catheter ablation, the Holter monitor showed deterioration, with a minimum heart rate of 29 beat per minute and a maximum RR interval of 4.18 seconds. Therefore, the patient's father received pacemaker implantation (Assurity $\mathrm{MRI}^{\mathrm{TM}}$, DDDR; St. Jude Medical, Inc.).

The patient's 4-year-old brother, who presented with no symptoms, was also found to have a first-degree AV block (Fig. 1B; PR interval, 180 ms). He had a large secundum ASD (Fig. 2C; maximum diameter, $10.7 \mathrm{~mm}$ ), which was closed percutaneously by implanting an Amplatzer septal occluder (14 mm; Fig. 2D) successfully without complication.

Within the family, the patient's paternal grandfather and great-grandmother died of unknown heart diseases at 37 years old and late 50s, respectively. The patient's mother denied any history of heart disease, and the sister's echocardiogram showed normal intracardiac structure without ASD (Fig. 3A).

Because there was a strong suspicion for familial autosomal

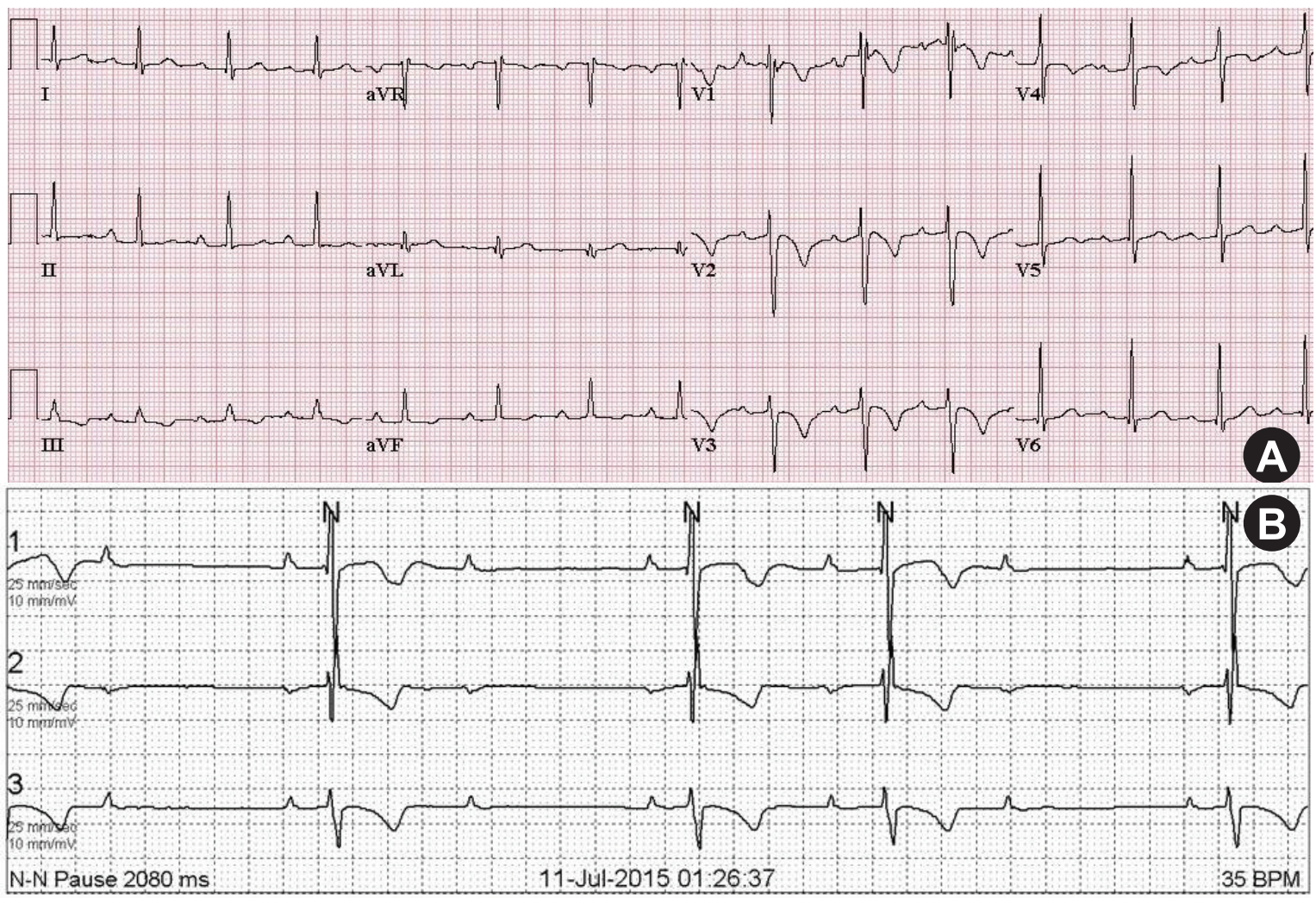

Fig. 1. Electrocardiography before atrial septal defect closure. (A) Electrocardiography of older brother showed sinus rhythm with PR interval of $220 \mathrm{~ms}$, which corresponds to first-degree atrioventricular block. The 98th percentile of the PR interval of 8 to 12 year old boy is 174 ms. (B) Electrocardiography of younger brother showed sinus rhythm with prolonged PR interval of $180 \mathrm{~ms}$. The 98th percentile of the PR interval of 3 to 5 year old boy is $152 \mathrm{~ms}$. 
dominant disorder, genetic testing for familial congenital heart defects was performed. In the affected family members, there were no major anomalies other than the heart, including skeletal deformity. Therefore, we considered the possibility of NKX2.5 and GATA4, which are typical genes causing non-syndromic

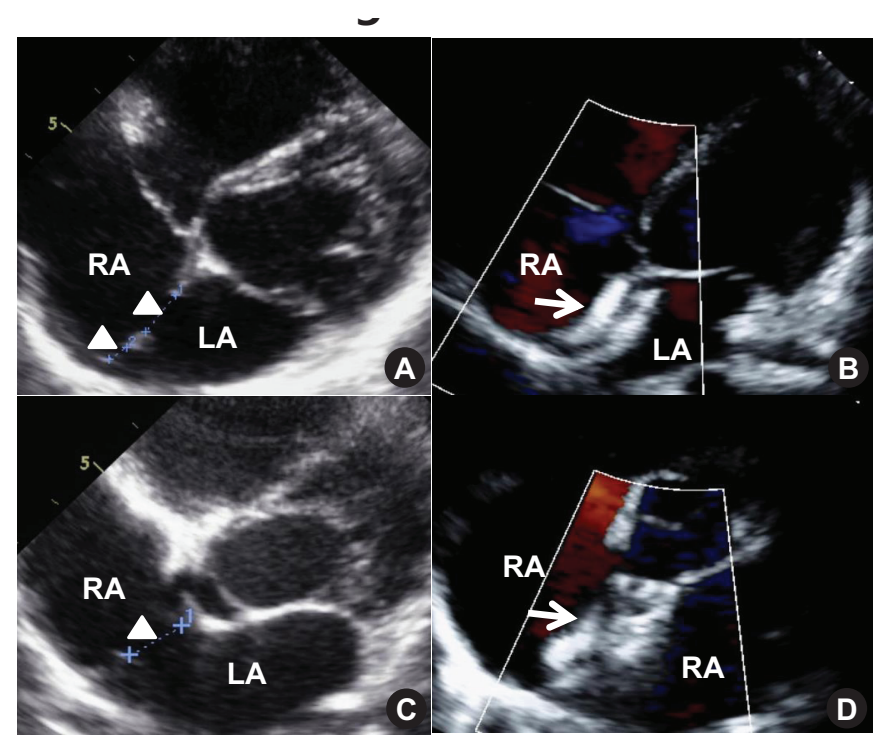

Fig. 2. Echocardiographic findings before and after device closure of atrial septal defect at the parasternal short axis view. (A) Older brother had two holes (10 and $4.4 \mathrm{~mm}$, indicated by the arrowheads) in atrial septum. (B) Larger defect was closed by Amplatzer septal occluder (17 $\mathrm{mm}$, indicated by the arrow) for the older brother. (C) Younger brother had one hole $(10.7 \mathrm{~mm}$, indicated by the arrowhead) in atrial septum. (D) Amplatzer septal occluder (14 $\mathrm{mm}$, indicated by the arrow) was implanted for younger brother.

$\mathrm{RA}$, right atrium; LA, left atrium. congenital heart malformations [1]. In addition, since the GATA4 mutation had been reported to be unrelated to the AV block, unlike the NKX2.5 mutation [5], we targeted the NKX2.5 first. We sequenced the coding exons of the NKX2.5 gene by Sanger's method and found a novel mutation in exon 2 of NKX2.5 from both sons and the father (Fig. 3B). All affected family members had a T deletion in chromosome 5: 172,659,796 (hg19) by Sanger sequencing, which is predicted to result in premature termination of transcription at 60 base pairs downstream of the mutation site.

Mutations in NKX2.5 were reported in a small proportion of patients with congenital hypothyroidism $[7,8]$. In our case, the boys' father had normal thyroid hormone levels. Although the sons were not tested for thyroid hormone levels, their newborn screening results for congenital hypothyroidism were normal and the children had no signs of congenital hypothyroidism.

Here, we report the first Korean family of familial ASD with AV conduction disturbances, with a novel mutation in NKX2.5.

\section{Discussion}

Currently, more than 60 NKX2.5 mutations have been reported [2]. Various degrees of conduction system abnormalities can develop, depending on mutation sites. Some mutations produce only AV blocks without morphological defects [1]. As in our case, progressive cardiomyopathy or conduction defect, due to NKX2.5 mutation, may occur even after ASD correction. This suggests that the $N K X 2.5$ gene plays an important role in developing the AV node, as well as maintaining function of the

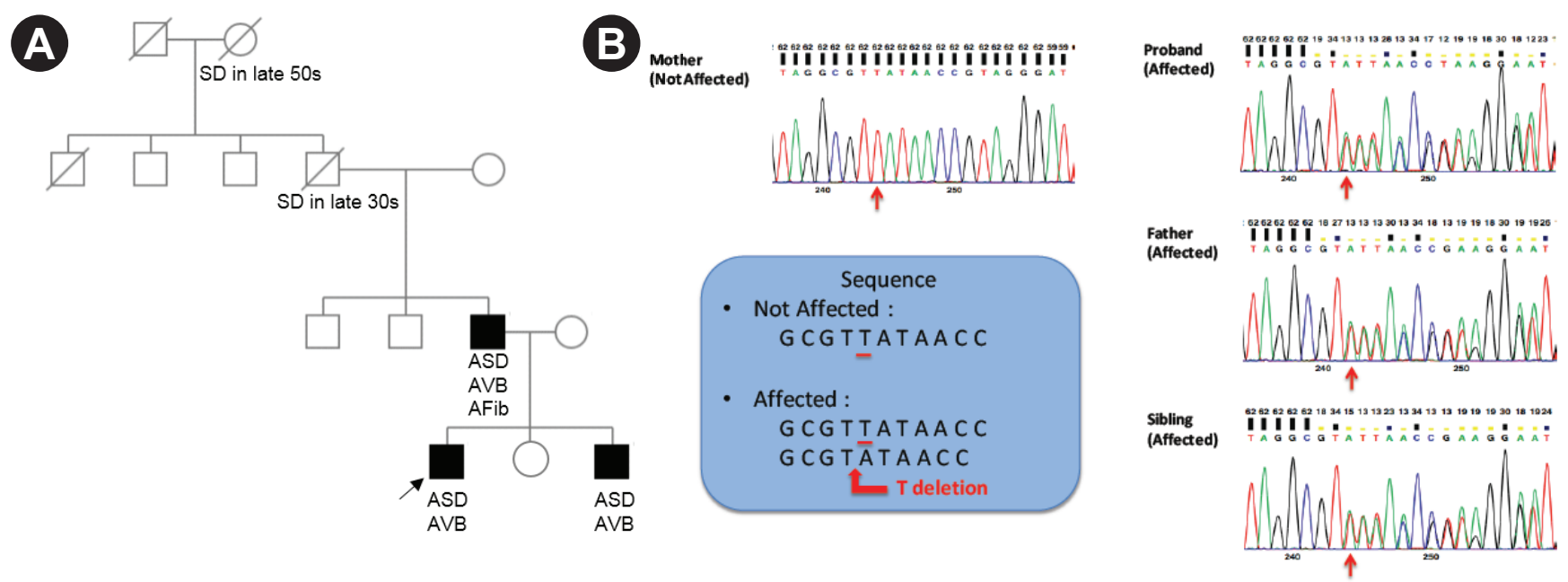

Fig. 3. Familial pedigree and genetic test results for family. Father and two brothers were affected by atrial septal defect (ASD) and atrioventricular block (AVB). T deletion in chromosome 5:172,659,796 (hg19) was found in the father and both sons by Sanger sequencing.

$\mathrm{SD}$, sudden death; AFib, atrial fibrillation. 
node throughout postnatal life [9]. In affected individuals, the prevalence of sudden death is high without a pacemaker. Sudden death may also occur after implantation of the pacemaker, presumably due to the ventricular arrhythmia associated with the NKX2.5 mutation $[2,10]$.

Genetic screening for mutations in NKX2.5 should be considered for patients with familial ASD and associated AV block. First degree relatives of patients with NKX2.5 mutations should be required to have examinations for ASD and conduction delay. Even if the test result is normal, the person may be an asymptomatic carrier with spontaneous ASD closure. Regular followup should be recommended for those who are likely to have the NKX2.5 mutation, because it is fatal and has high penetrance. Carriers should be monitored throughout the lifespan to determine appropriate timing of pacemaker or implantable cardioverter-defibrillator insertion [11]. The children in our case had marked conduction delays despite their young age. Although their ASDs were successfully closed, we plan to continue the follow-up visits at 1-year intervals.

In summary, a novel mutation of NKX2.5 was detected in a Korean family with ASD and AV block. This point mutation appeared to be strongly associated with progressive conduction delay, as well as the occurrence of secundum ASD. Therefore, clinicians should keep in mind that patients with NKX2.5 gene mutations may develop progressive arrhythmias, cardiomyopathy, and sudden cardiac death, regardless of ASD repair.

\section{References}

1. Schott JJ, Benson DW, Basson CT, Pease W, Silberbach GM, Moak JP, et al. Congenital heart disease caused by mutations in the transcription factor NKX2-5. Science 1998;281:108-11.
2. Ellesøe SG, Johansen MM, Bjerre JV, Hjortdal VE, Brunak S, Larsen LA. Familial atrial septal defect and sudden cardiac death: identification of a novel NKX2-5 mutation and a review of the literature. Congenit Heart Dis 2016;11:283-90.

3. McElhinney DB, Geiger E, Blinder J, Benson DW, Goldmuntz E. NKX2.5 mutations in patients with congenital heart disease. J Am Coll Cardiol 2003;42:1650-5.

4. Akazawa H, Komuro I. Cardiac transcription factor Csx/Nkx25: its role in cardiac development and diseases. Pharmacol Ther 2005;107:252-68.

5. Hirayama-Yamada K, Kamisago M, Akimoto K, Aotsuka H, Nakamura

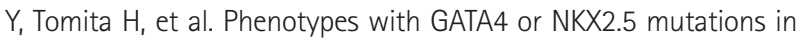
familial atrial septal defect. Am J Med Genet A 2005;135:47-52.

6. Rijnbeek PR, Witsenburg M, Schrama E, Hess J, Kors JA. New normal limits for the paediatric electrocardiogram. Eur Heart J 2001;22:70211.

7. Dentice M, Cordeddu V, Rosica A, Ferrara AM, Santarpia L, Salvatore D, et al. Missense mutation in the transcription factor NKX2-5: a novel molecular event in the pathogenesis of thyroid dysgenesis. J Clin Endocrinol Metab 2006;91:1428-33.

8. van Engelen $K_{1}$ Mommersteeg MT, Baars MJ, Lam J, Ilgun A, van Trotsenburg AS, et al. The ambiguous role of NKX2-5 mutations in thyroid dysgenesis. PLoS One 2012;7:e52685.

9. Pashmforoush M, Lu JT, Chen $H_{1}$ Amand TS, Kondo R, Pradervand $\mathrm{S}$, et al. Nkx2-5 pathways and congenital heart disease; loss of ventricular myocyte lineage specification leads to progressive cardiomyopathy and complete heart block. Cell 2004;117:373-86.

10. Maury P, Gandjbakhch E, Baruteau AE, Bessière F, Kyndt F, Bouvagnet $P$, et al. Cardiac phenotype and long-term follow-up of patients with mutations in NKX2-5 gene. J Am Coll Cardiol 2016;68:2389-90.

11. Gelernter-Yaniv $L$, Lorber A. The familial form of atrial septal defect. Acta Paediatr 2007;96:726-30. 